\title{
Avaliações da concentração de mercúrio total em solo e material particulado em áreas alagáveis na foz do rio Tapajós-PA, Fm. Alter do Chão, com auxílio de técnicas de sensoriamento remoto
}

\section{Evaluations of total mercury concentration in soil and particulate material in floodplains at the mouth of the river Tapajos-PA, Fm. Alter do Chão, using remote sensing techniques}

Enilson da Silva Sousa - Professor da Universidade Federal do Oeste do Pará (UFOPA); doutorando em Ciências Ambientais (CIAMB/UFG); mestre em Geociências, pela Univeirisidade Federal do Amazonas (UFAM). E-mail: prof.enilson@gmail.com

Marcelo de Oliveira Lima - Doutor em Química pela UFPA; pesquisador do Laboratório de Toxicologia da Seção de Meio Ambiente do Instituto Evandro Chagas (IEC), nas áreas de quimiometria, química analítica e toxicologia ambiental. E-mail: marcelolima@iec.pa.gov.br

Patricia Chaves de Oliveira - Doutora em Ciências Agrárias: Sistemas Agroflorestais pela UFRA; professora adjunta III da UFOPA.E-mail: pchaves@ufpa.br

Edson Eyji Sano - Doutor em Soil Science pela University of Arizona (USA); pesquisador da Empresa Brasileira de Pesquisa Agropecuária (EMBRAPA/Cerrado), Brasília-DF; bolsista de Produtividade em Pesquisa 2. E-mail: sano@cpac.embrapa.br

\section{Resumo}

Solos são as principais fontes de mercúrio $(\mathrm{Hg})$ para o sistema fluvial amazônico, especialmente em áreas alagáveis fluviais, principais sítios de metilação desse metal. O objetivo deste trabalho foi investigar a influência da Fm. Alter do Chão na dinâmica de $\mathrm{Hg}_{\text {tot }}$ e a variação e proporção deste metal em microbacias, drenado por esta formação geológica próxima a SantarémPA. Os procedimentos metodológicos incluíram: aquisição, processamento, análise de imagens de radar, imagens ópticas e dados interferométricos SRTM para confecção de mapas, georreferenciamento dos pontos de coleta e identificação da área da pesquisa; classificação, quantificação de material em suspensão e sedimentos das áreas identificadas na Fm. Alter do Chão para determinar o mercúrio total encontrado nas amostras e nível de contaminação por $\mathrm{Hg}_{\text {tot }}$ na foz do rio Tapajós.

\section{Palavras-chave}

Tapajós. Mercúrio. Áreas alagáveis. Radar.

\begin{abstract}
Soils are the main sources of mercury $(\mathrm{Hg})$ for the Amazon fluvial system, especially in fluvial floodplains, which are the main sites of methylation of this metal. The objective of this work was to investigate the influence of $\mathrm{Fm}$. Alter do Chao on the dynamics of $\mathrm{Hg}_{\text {Tot? }}$, which is drained by this geological formation, as well as the variation and proportion of this metal in micro watersheds, , near Santarém$\mathrm{Pa}$. The methodological procedures included: acquisition, processing, analysis of radar images, optical imaging and interferometric SRTM data for making maps, georeferencing of gathering points and identifying of the area of research; classification, quantification of suspended material and of sediments of the areas identified in Fm. Alter do Chão, in order to determine the total mercury found in the samples as well as the level of contamination by Hgtot at the mouth of the Tapajos River.
\end{abstract}

\section{Keywords}

Tapajós. Mercury. Foodplains. Radar. 


\section{INTRODUÇÃO}

O mercúrio $(\mathrm{Hg})$ é um metal pesado presente em todos os tributários da bacia amazônica. Parte deste metal possui origem antropogênica, proveniente do seu uso indiscriminado nos garimpos de ouro e atividades industriais, mas a maioria é aparentemente de origem natural (ROULET et al., 1998a; FADINI; JARDIM, 2001).

A concentração de $\mathrm{Hg}$ na maioria dos rios é variável, mas extremamente baixa e representa uma ameaça à saúde pública quando se encontra na forma de metil mercúrio $(\mathrm{MeHg})$, que é facilmente assimilado e bioacumulado na cadeia alimentar aquática, podendo contaminar populações ribeirinhas que dependem de peixe para obter proteínas.

Os principais reservatórios no ciclo global são: a atmosfera, o meio aquático e o solo, onde o mercúrio é presente principalmente na forma particulada $\mathrm{Hg}$ (p). Entre estes, o maior reservatório é o solo. Os fluxos incluem componentes naturais (emissões de vulcões e solos, deposição atmosférica, intemperismo físico e intemperismo químico) e antropogênica (emissões industriais, erosão antrópica etc.).

A mobilização de $\mathrm{Hg}$ nos solos e exporte para os sistemas fluviais é associada a condições hidromórficas, que são comuns em áreas alagáveis fluviais e interfluviais (GRIGAL, 2002). A erosão e o subsequente exporte na forma particulada também foi identificado como um importante mecanismo que contribui para a carga fluvial.

Figura 1: Esquema ilustrativo indicando os principais ciclos globais do mercúrio.

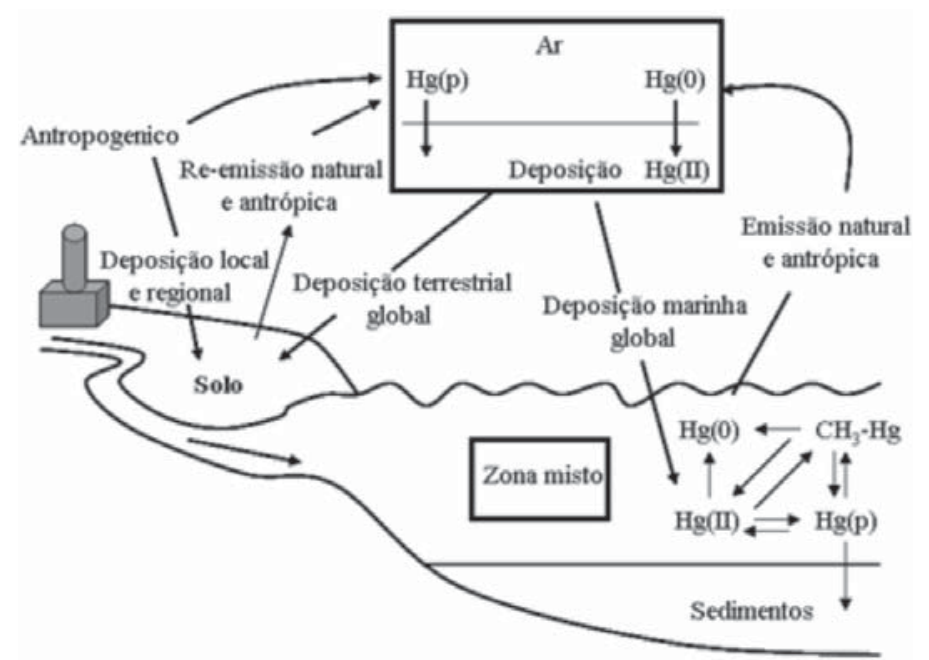

Fonte: Modificado de Mason et al. (1994).

Nota: Formação (Fm) Alter do Chão: Formação Geológica datada do Cretáceo-Terciário da Bacia do Amazonas, Carvalho et al. (2007).

Novos Cadernos NAEA • v. 15 n. 2 • p. 315-341 • dez. 2012 
Até o início da década de 1990, a poluição associada aos garimpos de ouro foi considerada a principal fonte de $\mathrm{Hg}$ na bacia amazônica (FORSBERG et al., 1995). Mais tarde, com a descoberta de elevados níveis de contaminação mercurial em solos, peixes e populações humanas, longe de qualquer atividade industrial, este conceito começou a mudar (FORSBERG et al., 1995; SILVAFORSBERG et al., 1999; ROULET et al., 1998). Hoje, sabe-se que a maioria do $\mathrm{Hg}$ na bacia é de origem natural.

As primeiras evidências da origem natural na Amazônia vêm de estudos com solos da bacia central amazônica, que são excepcionalmente ricos em mercúrio de origem natural (ROULET et al., 1998; ZEIDEMANN, 1998; FOSTIER, 1999; FADININI et al., 2001; LECHLER et al., 2000). Nesses estudos foi estimado que apenas o primeiro metro de solo na bacia do rio Negro contém 40 vezes mais mercúrio do que foi liberado pelo garimpo em toda a região amazônica durante os últimos 30 anos, e mais que 10 vezes a quantidade liberada pelos garimpos de ouro e prata em toda a América do Sul durante os últimos 500 anos (NRIAGU, 1994; FADINI; JARDIM, 2001).

Análises de $\mathrm{Hg}$ e outros elementos em águas do rio Tapajós indicaram que outro mecanismo pedológico está controlando a dinâmica do mercúrio nesta bacia (ROULET et al., 1998b). A maior parte de mercúrio nestas águas foi associada à fração particulada, indicando que o $\mathrm{Hg}_{\text {tot }}$ neste rio foi derivado predominantemente da erosão. Como o relevo na bacia do Tapajós é suave e existem evidências que as concentrações de material em suspensão têm aumentado recentemente (ROULET et al., 2001b), é provável que este mercúrio seja proveniente de erosão em áreas recentemente antropizadas, como áreas de mineração e terras agrícolas (ROULET et al., 1998b).

Ainda na década de 1990, pesquisadores brasileiros e canadenses encontraram concentrações bastante elevadas de mercúrio em solos amazônicos (WASSERMAN et al., 2001, em especial os solos hidromórficos e podzólicos. Para eles, o mercúrio formaria algum tipo de complexo com o ferro. A natureza desses complexos é ainda uma icógnita, já que a relação entre estes dois metais foi detectada a partir de coeficientes de correlação feitos em perfis de solo. Esta associação seria amplamente verificável em toda a Amazônia, assim, o mercúrio teria uma origem natural e não antropogênica como se imaginam (WASSERMAN et al., 2001) (Figura 2). Para Roulet et al. (1998a), seria necessário dez vezes mais garimpos para justificar as quantidades observadas, concluindo, assim, que $90 \%$ do mercúrio presente nos solos seria natural. 
Figura 2: O ciclo do mercúrio no ambiente amazônico.

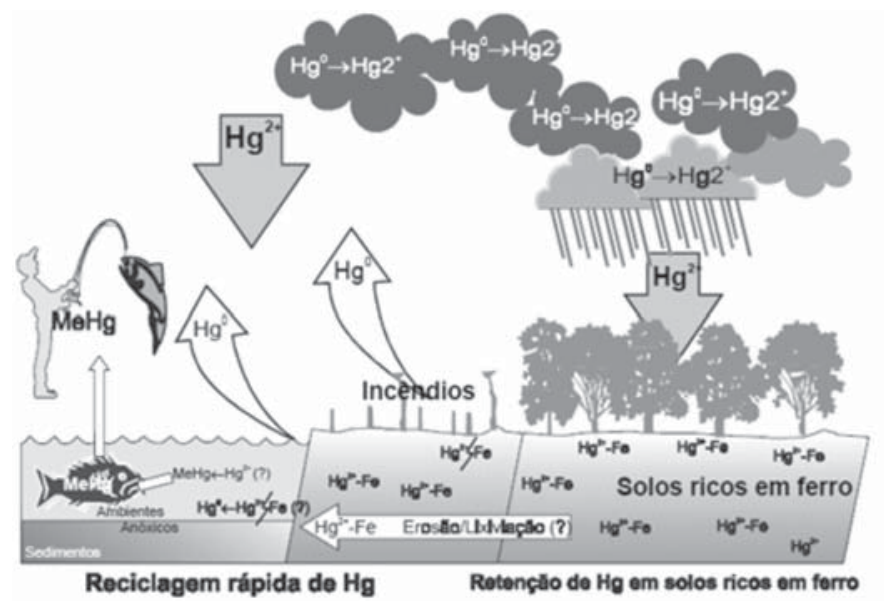

Fonte: Wasserman (2001).

O objetivo aqui é contribuir para o conhecimento do ciclo biogeoquímico do mercúrio na foz do rio Tapajós, através da observação quantitativa do mesmo em áreas alagáveis caracterizadas pela Fm. Alter do Chão, em Santarém-PA, tendo como objetivo específico investigar a dinâmica do mercúrio total ao longo da vários pontos de coleta na Fm. Alter do Chão (Santarém-PA) e investigar a dinâmica do mercúrio total ao longo da variação de profundidade dos solos.

Foram usadas nesta pesquisa imagens mosaicadas de radar do sistema JERS-1 apenas para caracterizar a rede hidrografia local, em especial para identificar as características das áreas alagadas na Fm. Alter do Chão e a sua correspondente local. A aquisição dessas imagens se deu junto ao Instituto Brasileiro dos Recursos Naturais Renováveis (IBAMA) - Estudo Matriz para o Projeto Manejo Sustentável dos Recursos Naturais da Várzea" (PROVARZEA, 2000) - Programa Piloto de Proteção das Florestas Tropicais do Brasil (PPG7) e não necessitaram de aplicação de técnicas de processamento digital.

\section{MATERIAL E MÉTODOS}

\subsection{Caracterizações da área da pesquisa}

A área estudada compreende a região coberta pela Fm Alter do Chão, na foz do rio Tapajós, município de Santarém, mesorregião do Baixo Amazonas e microrregião Santarém, na porção oeste do estado do Pará, coordenadas 02'25’30”S e 5442'50’W (IDESP/SEPOF-PA, 2011) (Figura 3), na Fl. SA.21, 
Projeto RADAM, 1976. Segundo o IBGE, para o ano de 2010, Santarém possui uma população de 294.580 habitantes, área de $22.887 \mathrm{~km}^{2}$ e densidade demográfica de $12,8 \mathrm{hab} / \mathrm{km}^{2} .{ }^{1}$

Figura 3: Mapa de localização da bacia do rio Tapajós e Santarém-PA.

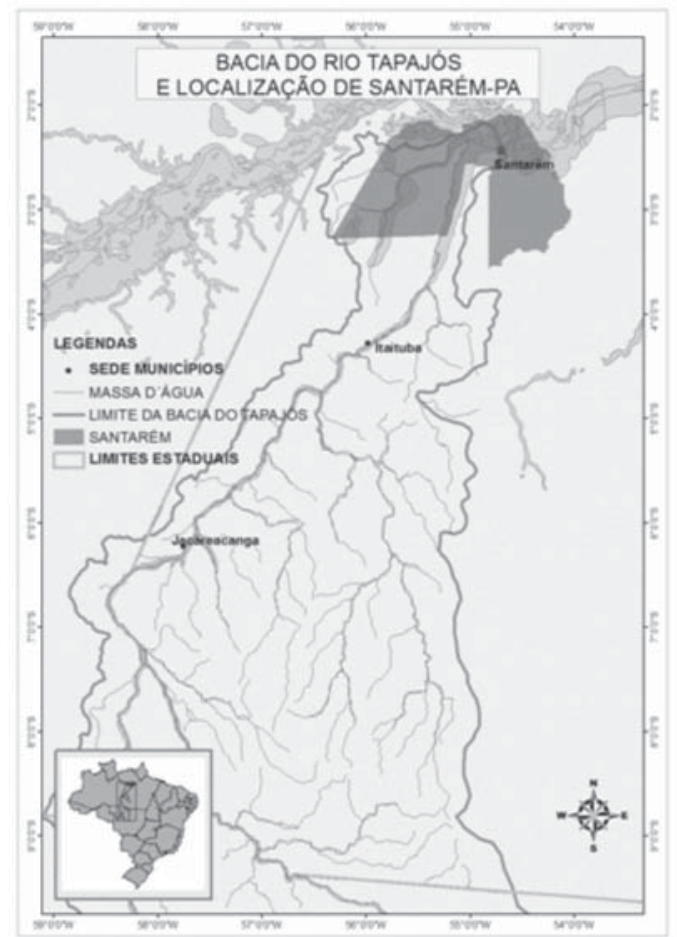

Fonte: Confeccionado pelos autores.

Segundo o Idesp/Sepof-PA (2011), a temperatura média anual é de $25,6^{\circ} \mathrm{C}$ e a umidade relativa com valores acima de $80 \%$ em quase todos os meses do ano. A pluviosidade se aproxima dos $2.000 \mathrm{~mm}$ anuais, com certa irregularidade durante todo o ano. As estações chuvosas coincidem com os meses de dezembro a junho, e as menos chuvosas com os meses de julho a novembro. O tipo climático da região é o $A m i$, (clima com mensal de temperatura mínima superior a $18^{\circ} \mathrm{C}$, estação seca de pequena duração e amplitude térmica inferior a $5^{\circ} \mathrm{C}$ entre o mês mais quente e o mês menos quente).

O excedente de água no solo, segundo o balanço hídrico, corresponde aos meses de fevereiro a julho, com um excedente de mais de $750 \mathrm{~mm}$, sendo março o mês de maior índice. A deficiência de água se intensifica entre agosto e dezembro, sendo setembro o mês de maior carência, ao constatar-se em menos de $90 \mathrm{~mm}$.

Disponível em: <http://www.ibge.gov.br/cidadesat>. Acesso em: 21 out. 2011. 
Segundo a classificação de Köppen, os tipos climáticos tropicais chuvosos (Afi, Ami e Awi), com base nas temperaturas médias dos meses que nunca são inferiores a $18^{\circ} \mathrm{C}$ e as variações do clima não têm verão ou inverno estacional. O clima Ami possui regime pluviométrico anual com uma estação relativamente seca, mas o total de chuvas é suficiente para manter o período (EMBRAPA, 2006).

A vegetação que predomina é do tipo floresta ombrófila densa latifoliada, comum das regiões tropicais, caracterizada por ser uma mata pesada e mista, que pode se apresentar com cobertura florestal de maneira uniforme ou presença de árvores emergentes. Em menor proporção, dependendo da região geomorfológica, aparecem savanas, campinaranas, refúgio ecológico, ora apresentando vegetação caracterizada como floresta de igapó, inundada permanentemente ao longo do ano. Em virtude das modificações antrópicas impressas na paisagem, principalmente nas duas últimas décadas, houve formação de áreas significativas de vegetação secundária (capoeiras) (ZEE BR-163, 2008).

\subsection{Formação Alter do Chão}

A escolha da Fm. Alter do Chão para desenvolver esta pesquisa deve-se, entre outros fatores, à associação de $\mathrm{Hg}$ aos solos lateríticos e à presença de área alagadas ou alagáveis, que, segundo Brabo (2010), são ambientes favoráveis e associados à presença desse metal. A Fm. Alter do Chão em Santarém apresenta os dois geossistemas. Outro fator levantado por Roulet et al. (1998a) é associado à origem antropogênica proveniente do uso indiscriminado de mercúrio em atividades garimpeiras - ou pelo desflorestamento, o que caracteriza a região da foz do Tapajós, Santarém-Formação Alter do Chão como uma área potencialmente associada à presença desse metal.

Segundo Sousa (2009), na porção oeste do estado do Pará, onde fica localizada a área de estudo, afloram poucas unidades litoestratigráficas de distribuição regional, essencialmente pertencentes à Formação Alter do Chão. Mas, por outro lado, é uma área que mostra grande diversidade de formas geomorfológicas e de relevo, sem, contudo, haver estudos detalhados. Para este autor, na área de estudo ocorrem somente litologias relacionadas ao Grupo Javari, em especial da Formação Alter do Chão (que compõe o Grupo Javari) e dos Depósitos Aluvionares Cenozóicos. A correlação estratigráfica entre vários perfis das rochas pertencentes à Fm. Alter do Chão na região de Santarém é mostrada na Tabela 1 e altimetria elaborada com base em dados SRTM (2001) (Figura 4). 
Tabela 1: Coluna estratigráfica simplificada da área de estudo.

\begin{tabular}{l|l|l}
\hline Idade & Unidade geológica & Litologias \\
\hline Terciário/Quaternário & $\begin{array}{l}\text { Aluviões modernos e } \\
\text { antigos }\end{array}$ & $\begin{array}{l}\text { Depósitos aluvionares inconsolida- } \\
\text { dos, sílticos, matéria orgânica }\end{array}$ \\
\hline Cretáceo/Terciáio & Formação Alter do Chão & $\begin{array}{l}\text { Lateritas imaturas } \\
\text { imaturos médios a grossos, } \\
\text { conglomeracos e níveis argilosos }\end{array}$ \\
\hline
\end{tabular}

Fonte: Sousa (2009).

Figura 4: Composição colrida mostrando a altimetria da área de estudo, elaborada com base nos dados SRTM (2001).

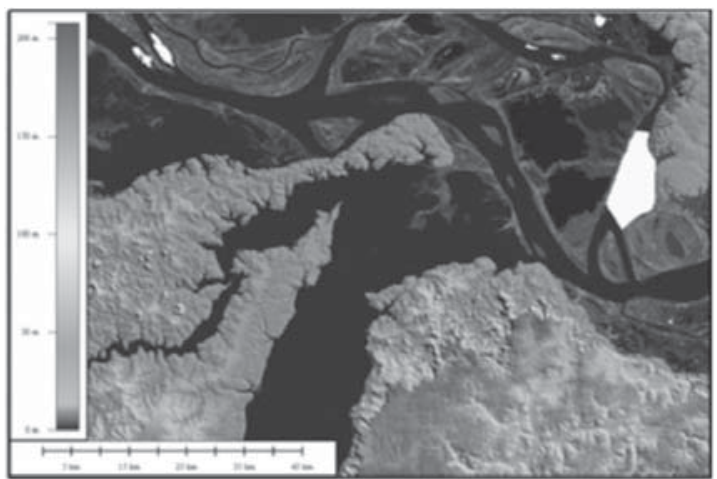

Fonte: Elaborado pelos autores, a partir de dados interferométricos SRTM (2001).

O conjunto estratigráfico da Fm. Alter do Chão é representado por pacote onde dominam arenitos brancos a róseos, médios a grossos, com intercalações conglomeráticas e bancos e níveis argilosos centimétricos a métricos extremamente contínuos lateralmente, assim como outros níveis estratigráficos permitem o fácil empilhamento estratigráfico, em função desta continuidade e constância em toda a área de estudo. A constituição granulométrica, estruturas presentes e espessura estimada são observados na Figura 5 e Tabela 2.

Figura 5: Perfis estratigráficos da Formação Alter do Chão e correspondentes correlações: Em (A) Perfil do Morro do Santarenzinho; (B) Perfil da Serra da Cambuquira; (C) Perfil do Morro da Lixeira; (D) Ponta do Cururu/rio Tapajós e (E) Rio Tapajós/Morro do Cruzeiro. Fonte: Sousa (2009).

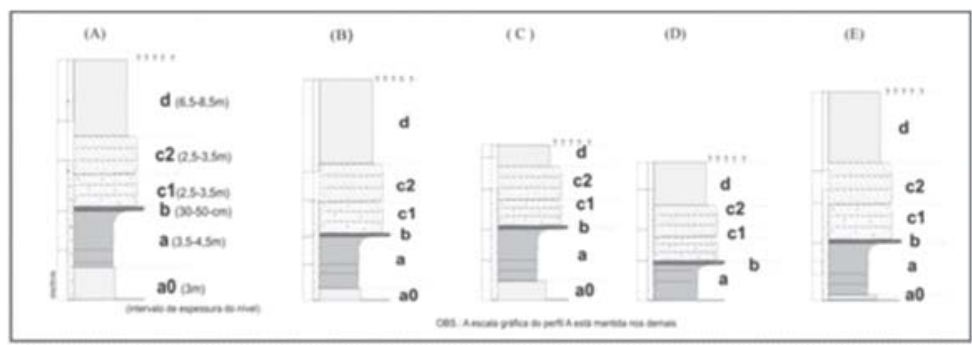

Novos Cadernos NAEA • v. 15 n. 2 • p. 315-341 • dez. 2012 
Tabela 2: Características litológicas e estratigráficas sedimentares dos níveis presentes estratigráficos da Fm. Alter do Chão na área de estudada.

\begin{tabular}{|c|c|c|}
\hline Nivel & Litologia & Estruturas sedimentares \\
\hline $\mathrm{d}$ & $\begin{array}{l}\text { Pacote de arenitos médios a finos, brancos, } \\
\text { amarelos a róseos, imaturos, finamente } \\
\text { laminados. Localmente silicificado. }\end{array}$ & $\begin{array}{l}\text { Estratificação plano parelela e cruzada } \\
\text { de baixo ângulo. }\end{array}$ \\
\hline $\mathrm{c} 2$ & $\begin{array}{l}\text { Pacote de arenitos médios a finos, por vezes } \\
\text { microconglomeráticos. }\end{array}$ & $\begin{array}{l}\text { Típica estratificação cruzada acanalada } \\
\text { de grande porte. }\end{array}$ \\
\hline $\mathrm{c} 1$ & $\begin{array}{l}\text { Pacote de arenitos grossos a médios, } \\
\text { microconglomeráticos e conglomeráticos, } \\
\text { lentes e níveis conglomeráticos, seixos bem } \\
\text { arredondados, bolas de argila. }\end{array}$ & $\begin{array}{l}\text { Estratificações cruzadas plano paralelas } \\
\text { e, por vezes acanaladas de pequeno a } \\
\text { médio porte. }\end{array}$ \\
\hline $\mathrm{b}$ & $\begin{array}{l}\text { Nível de conglomerado ferruginoso, delgado } \\
\text { (no máximo } 50 \mathrm{~cm} \text { ), seixos de arenito } \\
\text { ferruginosos, quartzo e arenitos friáveis, em } \\
\text { cimento bastante ferruginoso. }\end{array}$ & \\
\hline $\mathrm{a}$ & Pacote de argilitos cinza bastante homogêno. & Finamente laminado, maciço. \\
\hline $\mathrm{a} 0$ & $\begin{array}{l}\text { Pacote de arenitos ferruginosos, grossos, } \\
\text { com intercalações de níveis centimétricos de } \\
\text { conglomerados; em direção ao topo passam } \\
\text { para arenitos finos e friáveis e marcante } \\
\text { presença de níveis centimétricos de argilas. }\end{array}$ & $\begin{array}{l}\text { Estratificação cruzada plano-paralela de } \\
\text { pequeno a médio porte de alto ângulo. }\end{array}$ \\
\hline
\end{tabular}

Fonte: Sousa (2009).

\subsection{Localização dos pontos de coleta ao longo da Fm. Alter do Chão}

Para a seleção da área de coleta das amostras analisadas em laboratório, foi utilizado como metodologia 26 pontos para coleta de solo e sedimentos; e cinco pontos de coleta de material particulado, todos na área de abrangência da Fm Alter do Chão, em Santarém. As amostras localizam-se próximas à área urbana do município, na Rodovia Everaldo Martins (Igarapé do Juá), lagos do Juá e Itaparí, Ponta do Tauá (vila de Alter do Chão), Caminho das Pedras e Comunidade do Caranazal, no Lago Verde. Para coleta de material particulado, a Rodovia Everaldo Martins, lagos do Juá e Itaparí, Ponta do Tauá (vila de Alter do Chão) e Rodovia Everaldo Martins, nas proximidades da Serra do Cairé (Tabelas 3 e 4; Figuras 6 e 7).

Tabela 3: Pontos de coleta de solo e sedimentos.

\begin{tabular}{l|l|l}
\hline \multicolumn{1}{c|}{ Pontos / Descrição } & LAT em GEO & LONG em GEO \\
\hline PT 1A - Rod. Everado Martins & $02^{\circ} 26^{\prime} 43,3^{\prime \prime}$ & $54^{\circ} 47^{\prime} 14,1^{\prime \prime}$ \\
\hline PT 1B - Lago do Juá & $02^{\circ} 25^{\prime} 55,6^{\prime \prime}$ & $54^{\circ} 46^{\prime} 50,3^{\prime \prime}$ \\
\hline PT 2A - Lago do Itapari & $02^{\circ} 26^{\prime} 43,8^{\prime \prime}$ & $54^{\circ} 54^{\prime} 00,7^{\prime \prime}$ \\
\hline PT 3A - Alter do Chão: Ponta do Tauá & $02^{\circ} 29^{\prime} 05,2^{\prime \prime}$ & $54^{\circ} 58^{\prime} 18,2^{\prime \prime}$ \\
\hline PT 3B - Lago Verde: Caminho das Pedras & $02^{\circ} 31^{\prime} 12,2^{\prime \prime}$ & $54^{\circ} 55^{\prime} 50,1^{\prime \prime}$ \\
\hline PT 3C - Lago Verde: Caranazal & $02^{\circ} 31^{\prime} 18,6^{\prime \prime}$ & $54^{\circ} 55^{\prime} 49,7^{\prime \prime}$ \\
\hline
\end{tabular}

Fonte: Elaborado pelos autores resultante de pesquisa de campo. 
Tabela 4: Pontos de coleta de água (material particulado).

\begin{tabular}{l|l|l}
\hline \multicolumn{1}{c|}{ Pontos / Descrição } & LAT em GEO & LONG em GEO \\
\hline PT 1A - Igarape do Juá & $02^{\circ} 26^{\prime} 39,7^{\prime \prime}$ & $54^{\circ} 47^{\prime} 19,9^{\prime \prime}$ \\
\hline PT 1B - Lago do Juá & $02^{\circ} 25^{\prime} 55,6^{\prime \prime}$ & $54^{\circ} 46^{\prime} 50,3^{\prime \prime}$ \\
\hline PT 2A - Lago do Itapari & $02^{\circ} 26^{\prime} 41,5^{\prime \prime}$ & $54^{\circ} 53^{\prime} 58,8^{\prime \prime}$ \\
\hline PT 3A - Alter do Chão: Ponta do Tauá & $02^{\circ} 29^{\prime} 20^{\prime \prime}$ & $54^{\circ} 58^{\prime} 10^{\prime \prime}$ \\
\hline PT 3B - Rod. Everaldo Martins: prox. Serra do Cairé & $02^{\circ} 30^{\prime} 53,3^{\prime \prime}$ & $54^{\circ} 56^{\prime} 23,7^{\prime \prime}$ \\
\hline PT 3C - Lago Verde: Caranazal & $02^{\circ} 31^{\prime} 18,6^{\prime \prime}$ & $54^{\circ} 55^{\prime} 49,7^{\prime \prime}$ \\
\hline
\end{tabular}

Fonte: Elaborado pelos autores resultante de pesquisa de campo.

Figura 6: Localização dos pontos de coleta de solo, sedimentos e material particulado, shape file (IBGE, 2011).

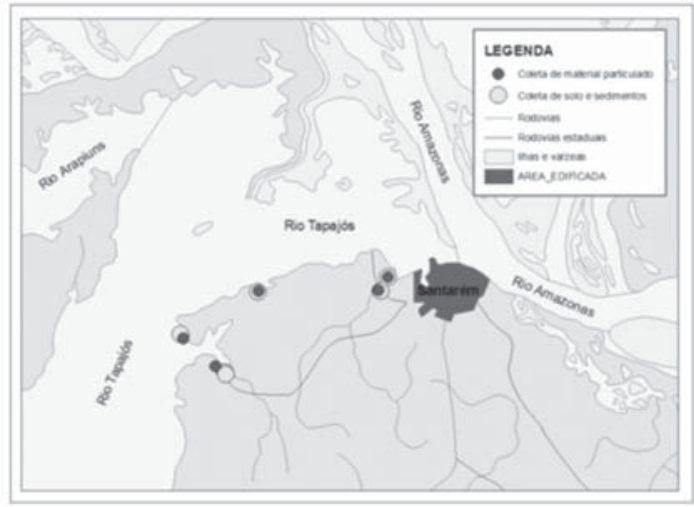

Figura 7: Imagem SRTM, com localização dos pontos de coleta de solo, sedimentos e material particulado.

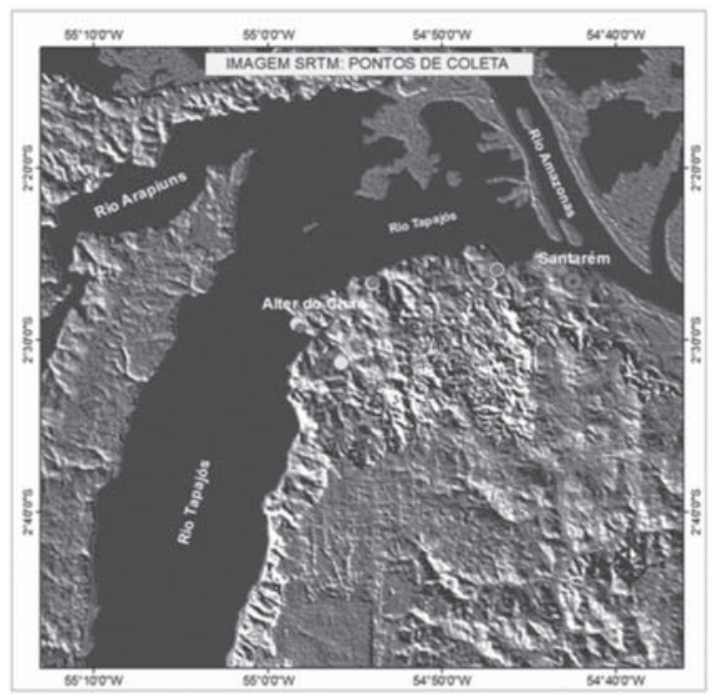

Fonte: Elaborado pelos autores, a partir de dados interferométricos SRTM, (2001), resultante de pesquisa de campo. 


\subsection{Aquisição e processamento de imagens e análises laboratoriais}

\section{a) Aquisição e processamento de imagens e dados de sensoriamento remoto}

Foram utilizados para corroborar as informações obtidas em campo e referencial teórico, mapas com dados interferométricos SRTM (Shuttle Radar Topography Mission) a partir download do site: http://www2.jpl.nasa.gov (link: <ftp://e0srp01u.ecs.nasa.gov>), da Agência Espacial dos Estados Unidos (NASA), onde estão disponíveis imagens da primeira e da segunda séries de processamento dos dados da SRTM.

Outos shapes files foram utilizados na confecção dos mapas de localização, entre eles podemos destacar os dados de arquivos shapes da Agência Nacional de Energia Elétrica (ANEL), página da web do Instituto Brasileiro de Geografia e Estatística IBGE (<www.ibge.gov.br>); e Companhia de Pesquisa de Recursos Minerais/Serviço Geológico do Brasil (CPRM).

O tratamento e processamento digital das imagens orbitais e dos shapes files foram realizados no Software Arc Gis (Arc Map 9.2), no Laboratório de Análise de Imagens da Embrapa Cerrado, em Brasília-DF. O datum South American Datum (SAD 69) foi usado no georreferenciamento das imagens e shape file neste trabalho.

\section{b) Avaliação dos teores de mercúrio em solos}

A metodologia utilizada para a análise química dos solos foi baseada em Mascarenhas et al. (2004), que utilizou amostras de sedimentos peneiradas na fração $<250$ mesh e o material particulado obtido por floculação com $\mathrm{Al}_{2} \mathrm{SO}_{4}$, para Rio Branco-AC. Uma massa de $250 \mathrm{mg}$ dos materiais foi submetido à digestão ácida e as determinações de $\mathrm{Hg}$ realizadas por Espectrofotometria de Absorção Atômica, com geração de vapor frio, no Laboratório de Toxicologia da Seção de Meio Ambiente (SAMAM) do Instituto Evandro Chagas (IEC), em Belém-PA.

A coleta do material analisado foi realizada na região do município de Santarém, entre a área urbana desse município e a vila de Alter do Chão, no período 26 a 30 de setembro de 2011, em seis pontos de amostragem, cada ponto com perfil estratigráfico de $60 \mathrm{~cm}$, subdividido em frações de 0-10, 10-20, 2030, 30-40 e 40-60 cm, durante o período de seca no estado do Pará; e todos os pontos encontram-se sobre a Fm. Alter do Chão.

A coleta das amostras de solo/sedimentos foi realizada com coletor em $\mathrm{T}$ de aço inoxidável. Após a amostragem foram separadas frações e armazenadas em 
sacos plásticos com espessura reforçada (Figura 6). A identificação das amostras ocorreu imediatamente com papel do tipo manteiga, com as informações dos pontos de amostragem escritos com lápis (grafite) dentro dos sacos com as amostras. Também foram identificados os sacos externamente com esparadrapo usando caneta esferográfica azul ou preta, para garantir que não ocorram perdas ou trocas na identificação das mesmas.

Para o material particulado, foram coletados cerca de 5 litros de amostras, em frascos de polipropileno. O procedimento de decantação/floculação com sulfato de alumínio, esvaziando o sobrenadante em campo e transferindo os resíduos úmidos para tubos do tipo Falcon. Quando houve necessidade de outro tipo de procedimento, em virtude das dificuldades logísticas na região amazônica, ocorreu o procedimento para material particulado/suspensão amostrado diretamente em frascos falcon (Figura 8) com centrifugação em campo, segundo o protocolo metodológico indicado pelo Laboratório SAMAM do IEC.

Figura 8: Fotos de materiais usados em trabalho de campo.

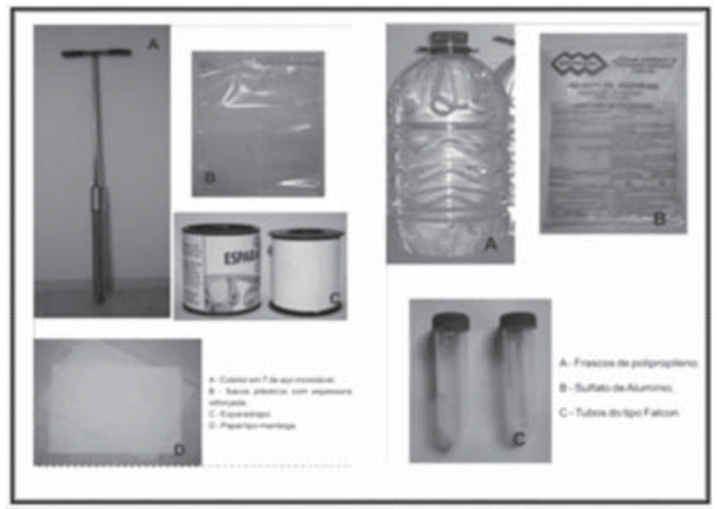

Fonte: Elaborado pelos autores durante a etapa de campo.

\section{RESULTADOS OBTIDOS}

Todos os procedimentos de análise de mercúrio total em amostras de solo/ sedimentos e material particulado da Formação Alter do Chão, município de Santarém-PA, foram realizados com base em normas nacionais e internacionais. A síntese metodologica pode ser assim descrita: secagem e separação granulométrica, pesagem de $200 \mathrm{mg}$ de cada amostra, digestão ácida e análise por CV-AAS. Os resultados de mercúrio total no material particulado foram relativamente altos para os pontos de coleta. Para exatidão analítica e comparação dos resultados obtidos dos teores de mercúrio total dos sedimentos de fundo e em material particulado, foi utilizado o Material de Referência Certificada (CRM) IAEA-SL-1 (Tabela 5). 
Tabela 5: Controle de Qualidade Analítica.

\begin{tabular}{c|c|c|c|c}
\hline \multicolumn{5}{c}{ Controle de qualidade analítica } \\
\hline CRM & Valor de Referência & $\mathrm{N}$ & Méda de Hg Total $(\mathrm{ug} / \mathrm{g})$ & $\%$ Recuperação \\
\hline IAEA-SL-1 & 0,18 & 5 & 0,183 & $101,7 \%$ \\
\hline
\end{tabular}

Fonte: Controle de Qualidade Analítica, do Instituto Evandro Chagas - IEC/Belém. Souza, (2004).

A determinação por digestão úmida/redução/espectrometria de absorção atômica por vapor frio (CVAAS) (sistema aberto de circulação do fluxo de ar), relaciona a redução de íons $\mathrm{Hg}^{2+}$ na solução da amostra com cloreto estanhoso para gerar vapor de mercúrio elementar $\left(\mathrm{Hg}^{0}\right)$; e a introdução de vapor de mercúrio na célula de foto-absorção para a medida de absorbância a 253,7 nm (SOUZA, 2004). Segundo a autora, este método pode ser aplicado diretamente à digestão de amostras biológicas, inclusive cabelo, sangue e peixe, como também várias amostras sólidas, como sedimento e solo.

Em laboratório, as amostras foram homogeneizadas com o método de quarteamento, passando por uma peneira de malha de 2,0 $\mathrm{mm}$, para preparar uma amostra para análise. As amostras que continham um conteúdo alto de água foram centrifugadas para remover o sobrenadante até ocorrer uma mistura bem homogeneizada antes de submetê-la à análise (SOUZA, 2004).

$\mathrm{Na}$ Figura 9 podem ser observados os resultados das análises de mercúrio total com granulometria para fração fina, para $\mathrm{Hg}_{\text {Total }}(\mu \mathrm{g} / \mathrm{g})$, nas regiões do Igarapé do Juá (Rodovia Everaldo Martins); Lago do Juá; Lago do Itapari; Alter do Chão: Ponta do Tauá; Lago Verde: Caminho das Pedras; Lago Verde: Caranazal, nos perfis de $0-10 ; 10-20 ; 20-30 ; 30-40$ e 40-60, para fração fina e fração bruta (Figura 10).

Figura 9: Resultados das análises de Mercúrio Total $(\mu \mathrm{g} / \mathrm{g})$ com granulometria para Fração Fina.

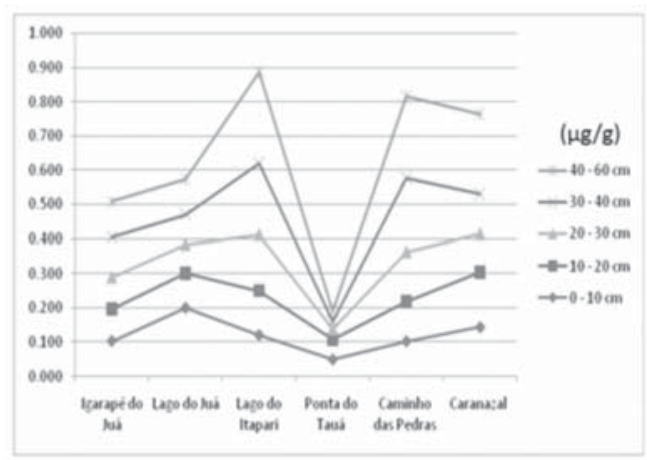

Novos Cadernos NAEA • v. 15 n. 2 • p. 315-341 • dez. 2012 
Figura 10: Resultados das análises de Mercúrio Total $(\mu \mathrm{g} / \mathrm{g})$ com granulometria para Fração Bruta.

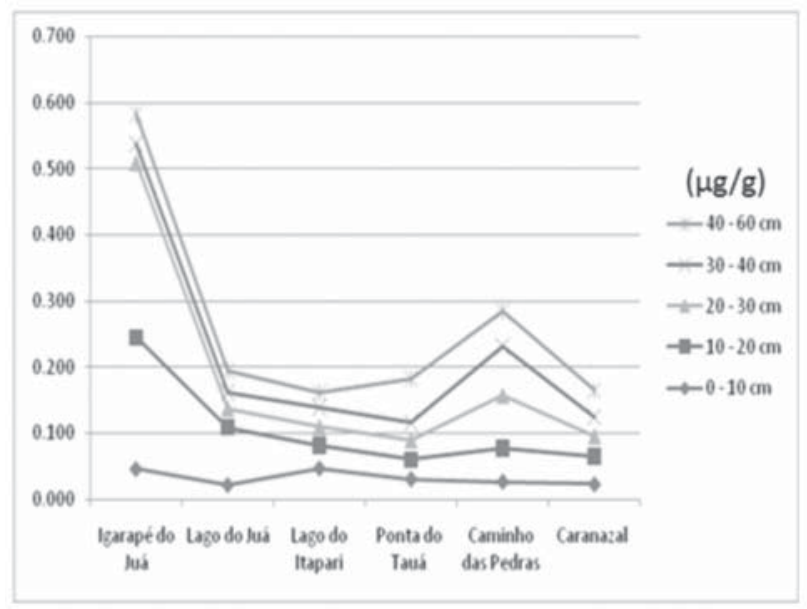

Na Figura 11 observa-se o nível de Mercúrio Total $(\mu \mathrm{g} / \mathrm{g}$ ) em material particulado nos pontos pesquisados.

Figura 11: Mercúrio Total ( $\mu \mathrm{g} / \mathrm{g})$ em material particulado.

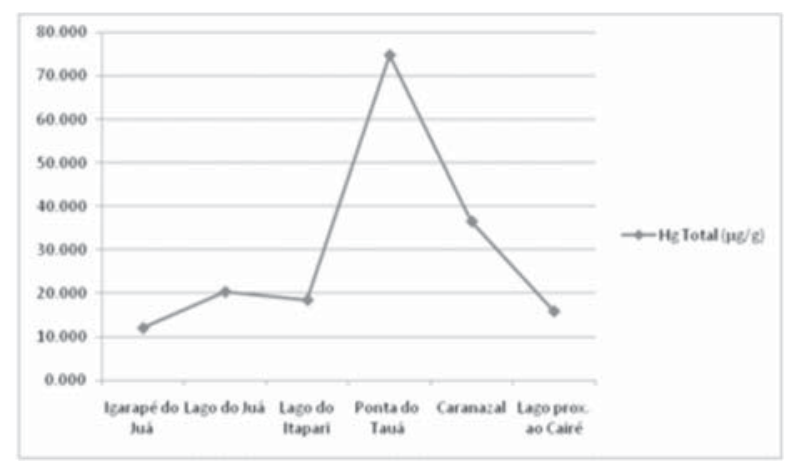

\subsection{Análises estatísticas dos resultados obtidos}

Para elaborar a análise estatística foram utilizados os testes de comparação de médias (Tukey), ANOVA Multivariada, de Distância multivariada (Teste de Penrose e Mahalanobis) e Teste de Hotteling. As análises foram feitas no programa BIOESTAT, versão 5.0 (AYRES et al., 2009) e realizadas as estatísticas descritivas.

$\mathrm{Na}$ Tabela 6 observa-se que quando o Coeficiente de Variação é de até $30 \%$ ou superiores, os valores são considerados significativos. Neste caso, foi 
observado que apenas em alguns pontos os valores não foram significativos, a exemplo de Igarapé do Juá, para fração fina, os valores foram de 9,68 \%, bem abaixo do esperado; Lago do Itapari, 28,42 \%, para fração bruta e Lago Verde, comunidade do Caranazal, para fração bruta, valores de 23,96\%, não significativos para essas amostragens. Os demais foram significativos.

Tabela 6: Resultados da estatística descritiva relativa às variações de mercúrio total $(\mu \mathrm{g} / \mathrm{g})$, na fração bruta (Fb) e fração fina, na Fm. Alter do Chão.

\begin{tabular}{|c|c|c|c|c|c|c|c|c|c|c|c|c|}
\hline$(\mu g / g)$ & $\begin{array}{l}\text { I. I. } \\
\text { (F.n }\end{array}$ & $\begin{array}{l}\text { I.J. } \\
\text { (F.b.) }\end{array}$ & $\begin{array}{l}\text { L.J. } \\
\text { (F. f) }\end{array}$ & $\begin{array}{l}\text { L.J. } \\
\text { (F. b.) }\end{array}$ & $\begin{array}{l}\text { L. I. } \\
\text { (E. f.) }\end{array}$ & $\begin{array}{l}\text { LI. } \\
(\mathrm{F}, \mathrm{b})\end{array}$ & $\begin{array}{l}\text { P.T. } \\
\text { (F.f) }\end{array}$ & $\begin{array}{l}\text { P. T. } \\
\text { (F. b.) }\end{array}$ & $\begin{array}{l}\text { C.P. } \\
(F . f .)\end{array}$ & $\begin{array}{l}\text { C. P, } \\
(\mathrm{F}, \mathrm{b})\end{array}$ & $\begin{array}{l}\text { L. V.C. } \\
\text { (F. f.) }\end{array}$ & $\begin{array}{l}\mathrm{L}, \mathrm{V}, \mathrm{C} \\
(\mathrm{F}, \mathrm{b})\end{array}$ \\
\hline $\begin{array}{c}\text { Tamanhe } \\
\text { da } \\
\text { amestra }=\end{array}$ & 5 & 5 & 5 & 5 & 5 & 5 & 5 & 5 & 5 & 5 & 5 & 5 \\
\hline Mínimo & 0.0930 & 0.0280 & 0.0840 & 0.0220 & 0.1200 & 0.0230 & 0.0240 & 0.0270 & 0.1020 & 0.0270 & 0.1110 & 0.0230 \\
\hline Màximo & 0.1170 & 0.2650 & 0.1990 & 0.0870 & 0.2690 & 0.0470 & 0.0590 & 0.0650 & $0.23 \times 0$ & 0.0810 & 0.2340 & 0.0420 \\
\hline $\begin{array}{c}\text { Amplitude } \\
\text { Total }\end{array}$ & 0.0240 & 0.2370 & 0.1150 & 0.0650 & 0.1490 & 0.0240 & 0.0350 & 0.0380 & 0.1360 & 0.0540 & 0.1230 & 0.0190 \\
\hline $\begin{array}{c}\text { Média } \\
\text { Aritmética }\end{array}$ & 0.1016 & 0.1166 & 0.1148 & 0.0390 & 0.1776 & 0.0324 & 0.0380 & 0.0364 & 0.1630 & 0.0570 & 0.1528 & 0.0330 \\
\hline Variânda & 0.0001 & 0.0117 & 0.0023 & 0.0007 & 0.0038 & 0.0001 & 0.0002 & 0.0003 & 0.0036 & 0.0004 & 0.0025 & 0.0001 \\
\hline $\begin{array}{l}\text { Dessio } \\
\text { Padrào }\end{array}$ & 0.0098 & 0.1081 & 0.0478 & 0.0272 & 0.0613 & 0.0092 & 0.0152 & 0.0161 & 0.0600 & 0.0212 & 0.0496 & 0.0079 \\
\hline $\begin{array}{c}\text { Coeficiente } \\
\text { de } \\
\text { Variacào }\end{array}$ & $9.68 \%$ & $92.74 \%$ & $41.64 \%$ & $69.68 \%$ & $34.53 \%$ & $28.42 \%$ & $39.91 \%$ & $44.11 \%$ & $36.84 \%$ & $37.11 \%$ & $3246 \%$ & $23.96 \%$ \\
\hline
\end{tabular}

Legenda: (*) I. J. - Igarapé do Juá; L. J. - Lago do Juá; L. I. - Lago do Itapari; P. T. - Ponta do Tauá; C. P.: Caminho das Pedras; L. V. C. - Lago Verde: Caranazal. (**) F. f. - Fração fina; F. g. - Fração grossa. Fonte: Elaborado pelos autores resultante de pesquisa de campo.

Na Tabela 7, adaptada de Brabo (2010), indica os índices de referência de mercúrio para a região do rio Tapajós.

Tabela 7: Concentração de mercúrio em solos e outros materiais de alteração intempérica da região do Tapajós-PA.

\begin{tabular}{lll}
\hline \multicolumn{1}{c}{ Área de estudo } & \multicolumn{1}{c}{$\mathrm{Hg}(\boldsymbol{\mu} \mathrm{g} / \mathrm{g})$} & \multicolumn{1}{c}{ Fonte } \\
\hline Região do Tapajós, PA & Latossolo: $0,090-210$ & ANGÉLICA (Informação Verbal) \\
\hline Região do Tapajós, PA & Latossolo: 0,207 & ROULET; LUCOTTE, 1995 \\
Região do Tapajós, PA & $\begin{array}{l}\text { Latossolo: } 0,100-0,222 \\
\text { Crosta Ferruginosa: } 0,088-0,385\end{array}$ & OLIVEIRA et al., 2001 \\
& $\begin{array}{l}\text { Horizonte de Transição: } 0,077-0,123 \\
\text { Saprolito: } 0,018-0,117\end{array}$ & \\
\hline
\end{tabular}

Fonte: Modificado de Brabo (2011).

Na Figura 12 os resultados apresentados são para análise de distância multivariada (Teste de Penrose e Mahalanobis) acerca da comparação de seis ambientes (A - Ig. do Juá; B - Lago do Juá; C - Lago do Itapari; D - Ponta do Tauá; E - Caminho das Pedras; F - Lago Verde: Caranazal), quanto aos teores de $\mathrm{Hg}_{\text {Total }}$ na fração bruta e fina do solo na Fm. Alter do Chão, Santarém-PA.

Novos Cadernos NAEA •v. 15 n. 2 • p. 315-341 • dez. 2012 
Nele pode ser observado que em C-F (Lago do Itapari-Lago Verde: Caranazal (C-F), foi identificada a menor distância entre a comparação dos dois ambientes para fração bruta e fina de $\mathrm{Hg}_{\text {Total }}$, assim como no ambiente C-D (Lago do Itapari-Caminho das Pedras) foram os encontrados os maiores índices desse metal e serão analisados mais adiante.

O teste de distância multivariada (Penrose e Mahalanobis) é um método estatístico (Penrose) que testa as distâncias multivariadas de duas ou mais populações, levando em consideração para o cálculo os dados sobre médias, variâncias e covariâncias. O teste de Mahalanobis considera ainda as correlações entre as variáveis, além dos valores numéricos utilizados no procedimento de Penrose. Os tamanhos das amostras podem ser iguais ou desiguais (AYRES, 2007).

Figura 12: Resultado da análise de Distância Multivariada (Teste de Penrose e Mahalanobis) acerca da comparação de seis ambientes (A - Ig. do Juá; B - Lago do Juá; C - Lago do Itapari; D - Ponta do Tauá; E - Caminho das Pedras; F - Lago Verde: Caranazal), quanto aos teores de $\mathrm{Hg}_{\text {Total }}$ na fração bruta e fina do solo na Fm. Alter do Chão, em Santarém-PA.

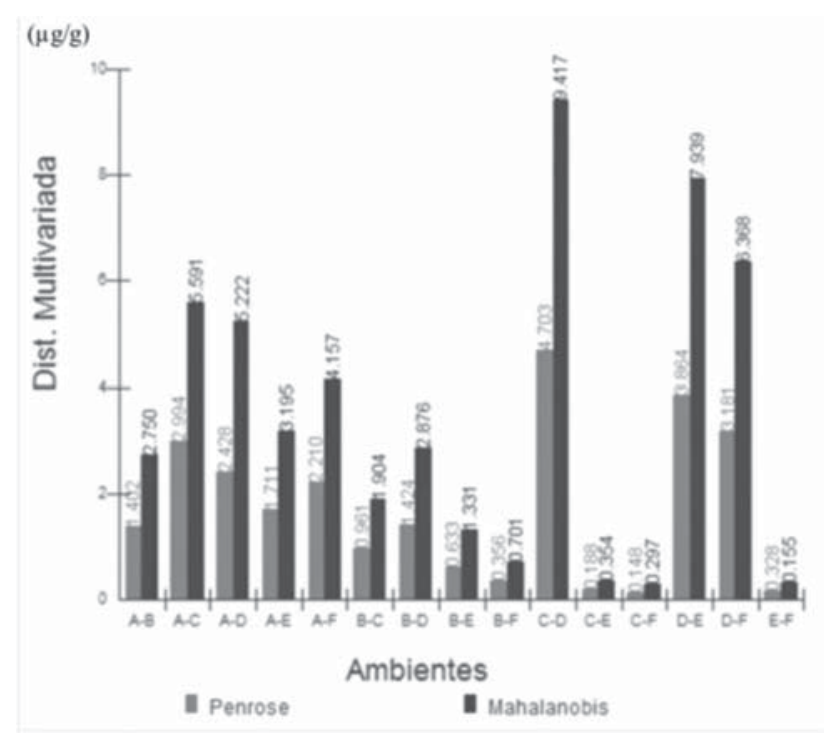

Com o objetivo de confirmar estatisticamente as informações observadas, foram realizados novos testes para certificar os resultados anteriores. O Teste de Tukey demonstrou ser bastante útil para esse fim. Este teste foi indicado para observar os resultados entre as comparações das diferenças entre as médias de $\mathrm{Hg}_{\text {Total }}$ nas áreas de estudo, sendo observado que apenas nas Colunas 3 - Lago do Itapari e 4 - Ponta do Tauá; Coluna 4 - Ponta do Tauá e Coluna 5 - Caminho 
das Pedras; Coluna 4 - Ponta do Tauá e Coluna 6 - Lago Verde: Caranazal, foram observados resultados significativos. Nas demais colunas, os resultados foram não significativos (ns) para $\mathrm{Hg}_{\text {Total }}$.

O Teste de Tukey foi utilizado para observar a semelhança e diferença entre os ambientes, com base em um conjunto de variáveis (Tabelas 8 e 9 e Figura 13). O teste estatístico ANOVA deriva da expressão inglesa ANalysis Of $V$ Ariance, chamando-se F-teste em homenagem a Fisher. Destina-se a comparar mais de duas amostras, cujos dados devem ser mensurados em escala intervalar ou de razões. A designação um critério é pelo fato de se comparar somente as variações entre os tratamentos, cujo resultado é traduzido no valor do F-teste, complementando-se com o exame a priori (Bonferroni) ou a posteriori (Tukey ou teste t de Student), das diferenças entre as médias amostrais. As amostras podem ser do mesmo tamanho ou desiguais (AYRES, 2007).

Tabela 8: Resultados do Teste de Tukey para comparação das diferenças entre as médias de $\mathrm{Hg}_{\text {Total }}$ da fração fina nos seis ambientes (1 - Ig. do Juá; 2 - Lago do Juá; 3 - Lago do Itapari; 4 - Ponta do Tauá; 5 - Caminho das Pedras; 6 - Lago Verde: Caranazal).

\begin{tabular}{|c|c|c|}
\hline Fonte de variação & $(\mu \mathrm{g} / \mathrm{g})$ & \\
\hline$(p)-$ & 0.0009 & \\
\hline Média $($ Coluna 1$)=$ & 0.1016 & \\
\hline Média $($ Coluna 2$)=$ & 0.1148 & \\
\hline Média $($ Coluna 3$)=$ & 0.1776 & \\
\hline Média $($ Coluna 4$)=$ & 0.0380 & \\
\hline Média $($ Coluna 5$)=$ & 0.1630 & \\
\hline Média $($ Coluna 6$)=$ & 0.1528 & \\
\hline Tukev. & Diferença & (p) \\
\hline Médias $(1$ a 2$)=$ & \begin{tabular}{|l|}
0.0132 \\
\end{tabular} & NS \\
\hline Médias $(1$ a 3$)=$ & 0.0760 & NS \\
\hline Médias $(1$ a 4$)=$ & 0.0636 & NS \\
\hline Médias $(1$ a 5$)=$ & 0.0614 & NS \\
\hline Médias $(1$ a 6$)=$ & 0.0512 & NS \\
\hline Médias $(2$ a 3$)=$ & 0.0628 & NS \\
\hline Médias $(2 \mathrm{a} 4)=$ & 0.0768 & NS \\
\hline Médias $(2$ a 5$)=$ & 0.0482 & NS \\
\hline Médias $(2$ a 6$)=$ & 0.0380 & NS \\
\hline Médias $(3$ a 4$)=$ & 0.1396 & $<0.01$ \\
\hline Médias $(3$ a 5$)=$ & 0.0146 & NS \\
\hline Médias $(3$ a 6$)=$ & 0.0248 & NS \\
\hline Médias $(4$ a 5$)=$ & 0.1250 & $<0.01$ \\
\hline Médias $(4$ a 6$)=$ & \begin{tabular}{|l|}
0.1148 \\
\end{tabular} & $<0.01$ \\
\hline Médias $(5$ a 6$)=$ & 0.0102 & NS \\
\hline
\end{tabular}

Legenda: Coluna 1: Ig. do Juá; Coluna 2 - Lago do Juá; Coluna 3 - Lago do Itapari; Coluna 4 - Ponta do Tauá; Coluna 5 - Caminho das Pedras; Coluna 6 - Lago Verde: Caranazal, para Fração Fina. NS: Não significativo. P: Probabilidade. 
Figura 13: Resultados do Teste de Tukey para comparação das diferenças entre as médias de $\mathrm{Hg}_{\text {Total }}$ da fração fina nos seis ambientes: 1 - Ig. do Juá; 2 - Lago do Juá; 3 - Lago do Itapari; 4 - Ponta do Tauá; 5 - Caminho das Pedras; 6 - Lago Verde: Caranazal.

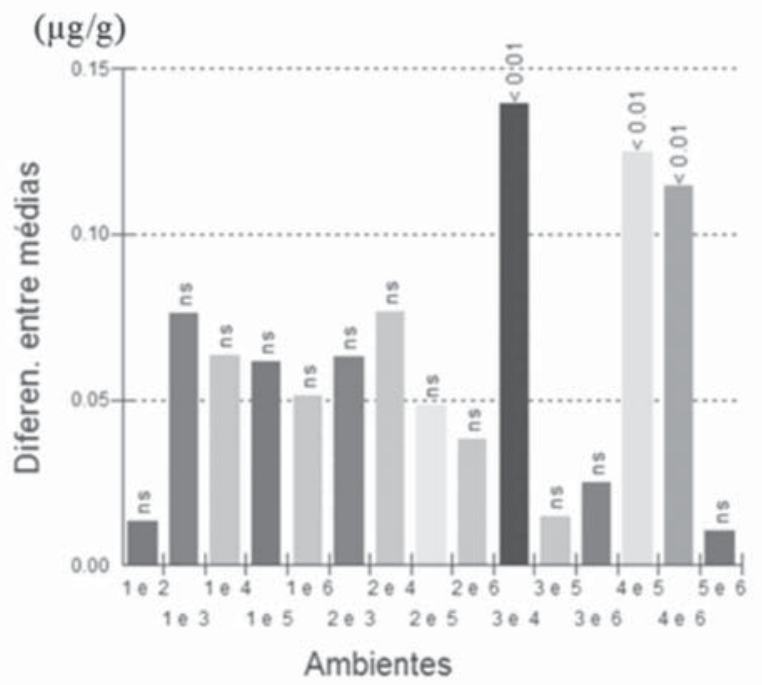

Legenda: NS: Não significativo.

Tabela 9: Resultados da análise de variância (Teste de Tukey) para comparação dos teores de mercúrio total $(\mu \mathrm{g} / \mathrm{g})$ nas frações brutas dos seis ambientes estudados, Fm. Alter do Chão.

\begin{tabular}{l|c|c|c}
\hline Fonte de variação & GL & SQ & QM \\
\hline Tratamentos & 5 & 0.027 & 0.005 \\
\hline$(\mu \mathrm{g} / \mathrm{g})(\mathrm{p})=$ & 0.0649 & & \\
\hline
\end{tabular}

Nas Tabelas 10 e 11 os resultados da análise multivariada através do Teste de Hotteling para comparação das concentrações de mercúrio total, tanto na fração fina quanto grossa, entre os ambientes do Lago do Itapari e Caminho das pedras, foram bastante significativos, enquanto que para os ambientes do Lago do Itapari e Lago Verde, comunidade do Caranazal, não foram significativos. Este fator levou à realização do Teste de Hotteling, para comparar as concentrações de mercúrio total nas frações finas e grossa entre os ambientes do Lago do Itapari-Caminho das Pedras e Lago do Itapari e Caranazal, para confirmar estatisticamente - fato observado visualmente nas Figuras 14 e 15.

O teste de Hotelling destina-se a comparar duas amostras multivariadas, cada uma com o mesmo número de variáveis - duas ou mais -, baseando-se 
na generalização do Teste $t$ de Student, mais precisamente no quadrado dessa estatística, sendo representado simbolicamente por T2. A probabilidade do teste - p-valor - é calculada pela estatística $F$ resultante da transformação de T2, conforme demonstrado no capítulo sobre Fórmulas Estatísticas. Os dados devem ser mensurados ao nível intervalar ou de razões (AYRES, 2007).

Tabela 10: Resultados da análise multivariada através do Teste de Hotteling para comparação das concentrações de mercúrio total tanto na fração fina quanto grossa, entre os ambientes do Lago do Itapari e Caminho das pedras.

\begin{tabular}{l|c|c}
\hline \multicolumn{1}{c|}{$(\mu \mathrm{g} / \mathrm{g})$} & $\begin{array}{c}\text { Var 1 } \\
\text { (Fração Fina) }\end{array}$ & $\begin{array}{c}\text { Var 2 } \\
\text { (Fração Grossa) }\end{array}$ \\
\hline Amostra 1 (Lago do Itapari): média $=$ & 0.1776 & 0.0324 \\
\hline Amostra 2 (Caminho das Pedras): média $=$ & 0.0380 & 0.0364 \\
\hline T2 (Hotteling) $=$ & 28.3982 & - \\
\hline $\mathrm{F}=$ & 12.4242 & - \\
\hline$(\mathrm{p})$ & 0.0052 & - \\
\hline
\end{tabular}

Tabela 11: Resultados da análise multivariada através do Teste de Hotteling para comparação das concentrações de mercúrio total $(\mu \mathrm{g} / \mathrm{g})$, tanto na fração fina quanto grossa, entre os ambientes Lago do Itapari e Caranazal.

\begin{tabular}{l|c|c}
\hline \multicolumn{1}{c|}{$(\mu \mathrm{g} / \mathrm{g})$} & $\begin{array}{c}\text { Var 1 } \\
\text { (Fração Fina) }\end{array}$ & $\begin{array}{c}\text { Var 2 } \\
\text { (Fração Grossa) }\end{array}$ \\
\hline Amostra 1 (Lago do Itapari): média $=$ & 0.1776 & 0.0324 \\
\hline Amostra 2 (Caranazal): média $=$ & 0.1528 & 0.0330 \\
\hline T2 (Hotteling) $=$ & 0.4972 & - \\
\hline F $=$ & 0.2176 & - \\
\hline (p) & 0.8097 & - \\
\hline
\end{tabular}

\subsection{Pranchas com aspectos mais importantes dos locais de coleta}

As pranchas com fotografias (Figuras 14a-h; 15a-h, 16a-d), servem para corroborar e ilustrar este trabalho e apresentar de forma visual os ambientes estudados e as condições de trabalho de campo. 
Figura 14a-h. A) Ecossistema do entorno do Igarapé do Juá, às margens da rodovia Everaldo Martins; B) Coleta de material particulado no Igarapé do Juá, às margens da rodovia Everaldo Martins; C) Ambiente do lago do Juá, onde foram coletadas amostras de solo-sedimento e material particulado; D) Coleta de material particulado no Lago do Juá; E) Coleta de solo no ambiente entorno do Lago do Juá; F) Ambiente do Lago do Preto, na comunidade do Itapari, margem direita do rio Tapajós, Santarém-PA; G) Lago do Preto, comunidade do Itapari, margem direita do rio Tapajós, Santarém-PA; H) Coleta de solo no ambiente entorno do Lago do Itapari.

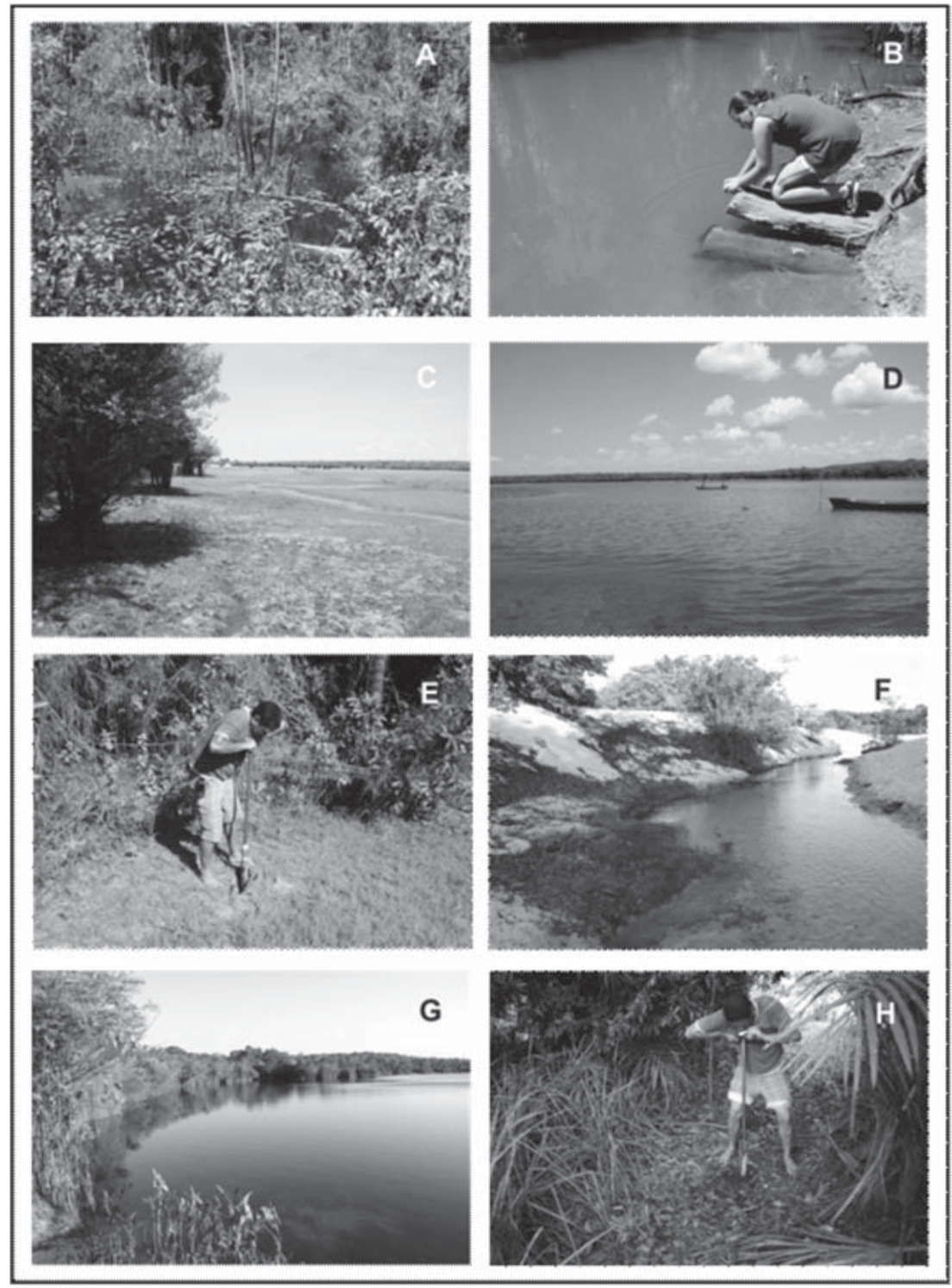

Novos Cadernos NAEA • v. 15 n. $2 \cdot$ p. 315-341 • dez. 2012 
Figura 15a-h. A) Ambiente do Lago Verde, comunidade do Caranazal, às margens da Rodovia Everaldo Martins, próximo a Vila de Alter do Chão; B) Panorama do Lago Verde, comunidade do Caranazal, às margens da Rodovia Everaldo Martins, próximo a Vila de Alter do Chão; C) Coleta de material particulado no Lago Verde; D) Panorama da Ponta do Tauá, na vila de Alter do Chão; E) Panorama da Ponta do Tauá, vila de Alter do Chão, visual da Fm. Alter do Chão; F) Fm. Alter do Chão, Ponta do Tauá, Alter do Chão; G) Coleta de solo na Ponta do Tauá, vila de Alter do Chão; H) Lago próximo a Serra do Cairé, Rodovia Everaldo Martins, Vila de Alter do Chão.

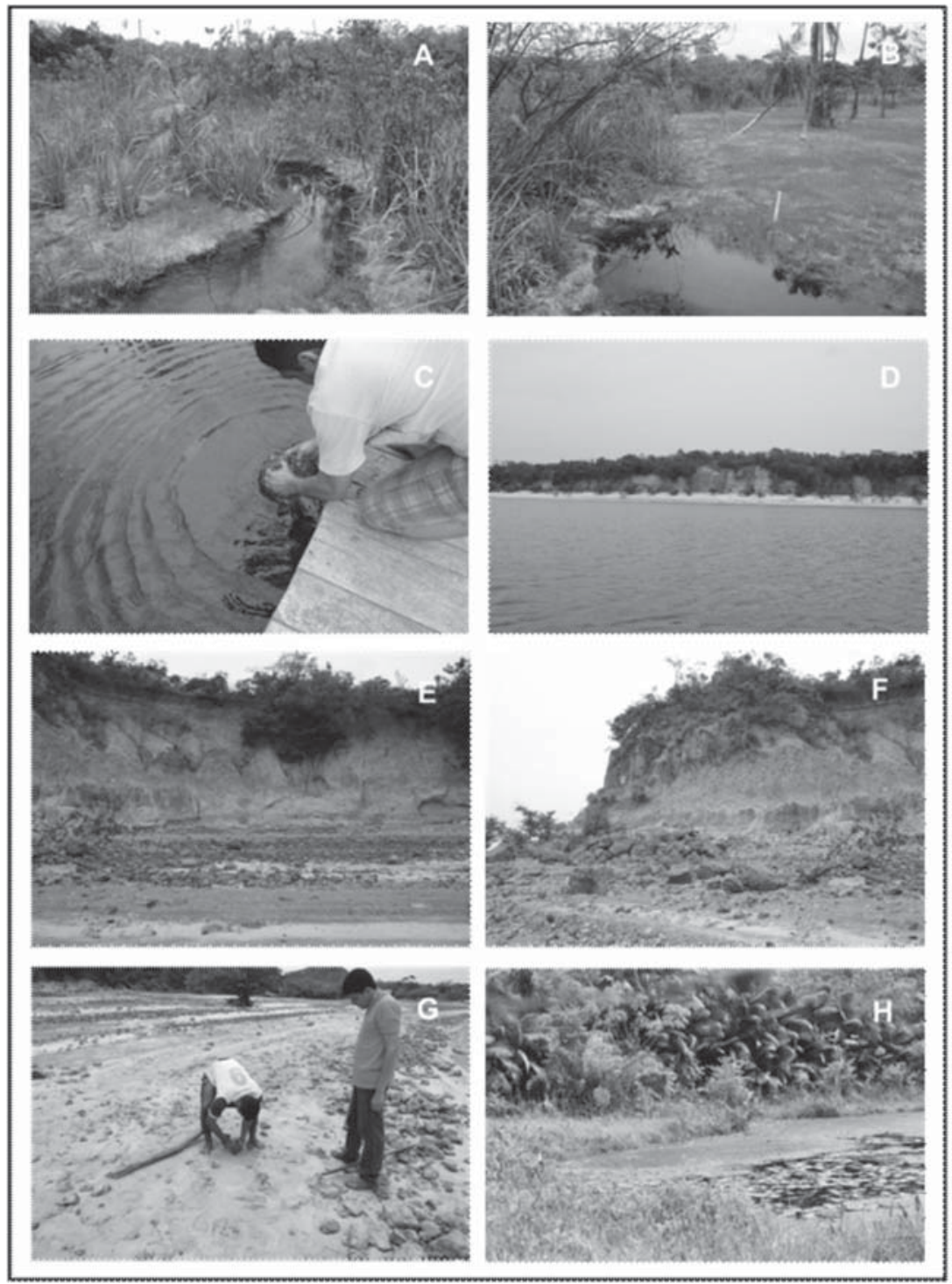

Novos Cadernos NAEA • v. 15 n. $2 \cdot$ p. 315-341 • dez. 2012 
Figura 16a-d. A) Panorama do Lago próximo a Serra do Cairé, Rodovia Everaldo Martins, Vila de Alter do Chão; B) Coleta de material particulado no lago próximo a Serra do Cairé; C) Panorama do Lago Verde no Caminho das Pedras, Vila de Alter do Chão; D) Amostras de solo do Lago Verde no Caminho das Pedras, Vila de Alter do Chão.

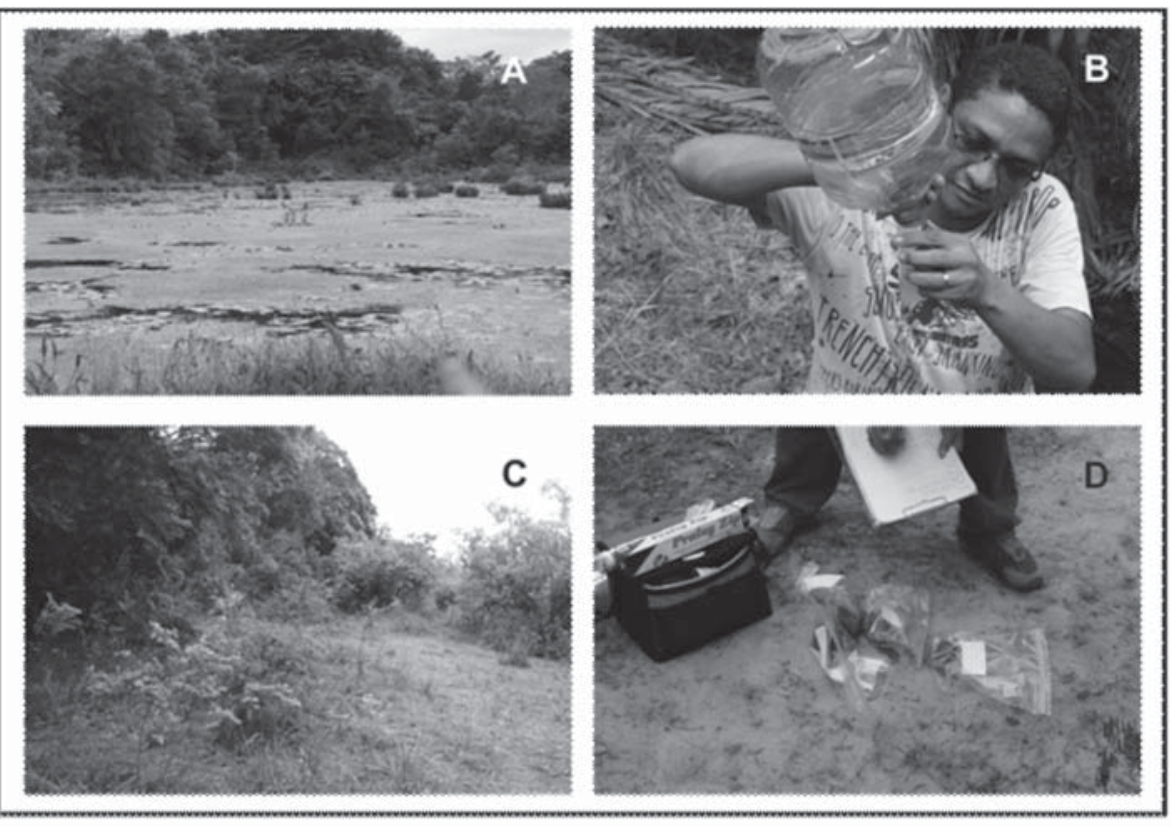

\section{RESULTADOS E CONCLUSÕES}

Na literatura que aborda a temática de mercúrio na bacia central amazônica, várias propostas são apresentadas na tentativa de se estabelecer um modelo para o ciclo do mercúrio em nível global e amazônico (BRABO, 2010). No entanto, ainda não existe consenso, no que diz respeito à emissão natural e antropogênica nos ambientes da região pesquisada. $\mathrm{Na}$ última década, o comportamento do solo como emissor mercurial para o ambiente vem sendo estudado e indica ser uma das principais fontes de metal para o ambiente. Entretanto, devido ao grande número de variáveis envolvidas e às complexidades das reações, ocorrem diferentes compartimentos ambientais, tornando-se difícil estabelecer uma proposta capaz de relacionar todas estas interações e chegar a um modelo único (BRABO, 2010).

Com base nessa linha de raciocínio, foi elaborado este ensaio sobre a liberação de $\mathrm{Hg}_{\text {Total }}$, pela Fm. Alter do Chão na região entre a cidade de Santarém e a Vila de Alter do Chão, na bacia do rio Tapajós, estado do Pará. Neste sentido, 
o presente trabalho propôs avaliar o comportamento do $\mathrm{Hg}_{\text {Total }}$ nos perfis de alteração desenvolvidos em diferentes substratos geológicos e material particulado em ambientes próximos, como uma contribuição que possa ser utilizada para o entendimento do ciclo do $\mathrm{Hg}$ na região. Para tal, foram realizados diversos perfis do solo na formação e coleta de material particulado para avaliar sua relação com o mercúrio pesquisado.

Mascarenhas (2004) afirma que a determinação de $\mathrm{Hg}$ em sedimentos de fundo constitui importante referencial para a avaliação da poluição de ambientes aquáticos por metais pesados e a determinação de $\mathrm{Hg}$ em material particulado suspenso representa um papel importante, considerando os aspectos relacionados ao transporte e mobilidade deste metal, visto que a granulometria fina em suspensão pode adsorver e trocar íons com a solução, transportando-os ao longo do corpo d'água e depositando em outros sítios.

Para este autor, o mercúrio e outros metais pesados em ambientes aquáticos ligam-se predominantemente ao material particulado em suspensão, o que pode indicar que o mercúrio particulado encontrado, principalmente em Alter do Chão, na Ponta do Tauá, pode estar vindo de ambientes próximos, no contexto da Fm. Alter do Chão. Na área pesquisada, para o material particulado, foi observado pico de $\mathrm{Hg}_{\text {Total }}$ na Ponta do Tauá, foz do Lago Verde, que possui desembocadura dentro do rio Tapajós, o menor índice no igarapé do Juá, às margens da Rodovia Everaldo Martins, em direção ao Aeroporto Maestro Wilson Fonseca. Os resultados obtidos indicam que nos perfis de solo, ficaram dentro dos índices esperados para os rios amazônicos não poluídos (MASCARENHAS, 2004), no entanto, os níveis de mercúrio total em material particulado foram relativamente elevados, indicando que novos levantamentos devem ser realizados para corroborar os índices alcançados por este trabalho.

Os teores de $\mathrm{Hg}_{\text {Total }}$ nos solos-sedimentos para fração bruta variaram entre 0,022 e 0,199-265 $\mu \mathrm{g} / \mathrm{g}$, sendo os menores valores encontrados no Lago do Juá e maiores no Igarapé do Juá, com média de 0,0324 \pm 0,1166 $\mu \mathrm{g} / \mathrm{g}$; Lago do Itapari e Igarapé do Juá, 0,0380 e 0,1776 $\mu \mathrm{g} / \mathrm{g}$, respectivamente; Ponta do Tauá, na Vila de Alter do Chão e Lago do Itapari, para fração fina. Para o material particulado, os resultados de mercúrio total foram relativamente altos; a variação foi de 12,050 a $74,880 \mu \mathrm{g} / \mathrm{g}$. Neste caso, sugerimos novos estudos para ratificar ou não os resultados apresentados, como se observa nos resultados obtidos (Tabela 3).

Brabo (2010), que desenvolveu um importante trabalho na tese de doutorado Geoquímica do mercúrio na bacia do rio Tapajós, publicado pela Editora do Instituto Evandro Chagas, em Belém, afirma que apenas a avaliação das concentrações de $\mathrm{Hg}$ total e outras análises de perfis não são suficientes para 
afirmar que a presença seja atribuída única e exclusivamente à contribuição natural, sem mais informações sobre a evolução pedológica que resultem em mudanças estruturais e na composição química e mineralógica destes materiais. Este autor afirma que a presença de mercúrio no solo e outros materiais de alteração supergênica na região amazônica mostraram que, independentemente do contexto onde a área está inserida, os valores de mercúrio, com algumas exceções, são relativamente elevados, quando comparados com os valores tidos como referência para ocorrência desse metal.

Considerando que na região pesquisada não há registro de atividades garimpeiras ao longo de sua história, fato que poderia justificar a concentração de $\mathrm{Hg}$ no ambiente e atividades antropogênicas, como a concentração significativa de indústrias, são indicativos de que o solo pode apontar para presença desse metal em níveis consideráveis, especialmente para contribuição em material particulado, mesmo sem dispor de dados que possam comprovar de forma definitiva a procedência e as rotas de migração predominantes do Hg nessas áreas.

Recomenda-se que pesquisas complementares sejam desenvolvidas para elucidar a origem e os processos de disponibilidade do mercúrio na região, especialmente na Fm. Alter do Chão, objeto desse estudo deste trabalho, para corroborar as demais pesquisas sobre mercúrio em toda a bacia amazônica, especialmente na Amazônia central, onde a bacia do rio Tapajós e Fm. Alter do Chão estão inseridos.

\section{REFERÊNCIAS}

ANDRADE, H.; SCHAEFER, C. E. G. R.; DEMATTÊ, J. L. I; ANDRADE, F. VAZ. Pedogeomorfologia e micropedologia de uma sequência latossolo areia quartzosa hidromórfica sobre rochas cristalinas do estado do Amazonas. Geonomos, v. 5, n. 1, p. 55-66, 1997.

AYRES, M. et al. Bioestat: aplicações estatísticas nas áreas das ciências biomédicas. Belém: Mamirauá, 2007.

BELGER, L.; FORSBERG, B.R. Factors controlling mercury levels in two predatory fish species in the Negro river basin, Brazilian Amazon. Science of the Total Environment, v.367, p.451-459, 2006.

BLOOM, N. S. Determination of picogram levels of methylmercury by aqueous phase ethylation, followed by cryogenic gas chromatography with cold vapor atomic fluorescence detection. Can. J. Fish. Aquat. Sci., v. 46, p.1131-1140, 1989. 
BRABO, E. S. Geoquímica do mercúrio na bacia do rio Tapajós In: JESUS, I. M. et al. (Org.). Geoquímica do mercúrio na bacia do Rio Tapajós: do natural ao antropogênico. Ananindeua: Editora IEC, 2010. 300 p.

BRABO, E. S.; SANTOS, E. O.; JESUS, I. M.; MASCARENHAS, A. F.; FAIAL, K. F. Mercury level in fish consumed by the Sai Cinza indigenous community, Muduruku Reservation, Jacareacanga Coutry, State of Pará Brasil. Cad. Saúde Pública, Rio de Janeiro, v. 15, n.2, p.325-331, abr.-jun., 1999.

BRASIL. Departamento Nacional de Produção Mineral. Projeto RADAMBRASIL. Folha SA.21-SANTARÉM. Rio de Janeiro, 1976.

CARVALHO, A. S.; MILLIOTI, C. A.; PALHA, W.S.M. Caracterização Física da área de Influência da BR-319 no Estado do Amazonas (ManausPorto Velho no Trecho entre o km 250 ao km 655,7): Síntese da Geologia, Geomorfologia e Solos. Manaus: UFAM, 2007.

CUNHA, N. G. Considerações sobre os solos da sub-região da nhecolândia, Pantanal mato-grossense. Corumbá: EMBRAPA-UEPAE, 1990. (Circular Técnica, 01).

EMBRAPA Amazônia Oriental. Sistemas de Produção. 4-2 ed. Versão Eletrônica Dez./2006. Disponível em: <http://sistemasdeproducao.cnptia. embrapa.br>. Acesso em: 21 out. 2011.

ESPINDOLA, C. R. Retrospectiva crítica sobre a pedologia. Campinas: Ed. Unicamp, 2008.

FADINI, P. S.; JARDIM, W. F. Is the Negro River Basin (Amazon) impacted by naturally occurring Hg? Sci Total Environ., v. 275, p.71-82, 2001.

FORSBERG, B. R.; FORSBERG, M. C. S.; PADOVANI, C. R.; SARGENTINI, E.; MALM, O. High levels in fish and human hair from the rio Negro (Brazilian Amazon): Natural background or anthropogenic contamination. In: INTERNATIONAL WORKSHOP ON ENVIRONMENTAL MERCURY POLLUTION AND ITS HEALTH EFFECTS IN THE AMAZON RIVER BASIN. 1995. Rio de Janeiro. Proceedings... Rio de Janeiro: Nat. Inst. for Minamata Disease/Federal University of Rio de Janeiro, 1995. p. 33-40.

FORSBERG, B.R. Causas e Conseqüências da Contaminação Mercurial na Bacia Amazônica. No prelo. 
FOSTIER, A. H. et al. Mercury accumulation in natural forested Amazonian soils. In: INTERNATIONAL CONFERENCE ON MERCURY AS A GLOBAL POLLUTANT, 15. 1999. Rio de Janeiro. Proceedings... Rio de Janeiro, 1999. p. 557.

GRIGAL, D. F. Inputs and outputs of mercury from terrestrial watersheds: a review. Environ. Rev., Canadá, v. 10, 2002.

GUIMARÃES, J. R. D. et al. Hg net methylation in five tropical flood plain regions of Brazil: high in the root zone of floating macrophyte mats but low in surface sediments and flooded soils. Sci. Total Environ., v. 261, p. 99-107, 2000a.

GUIMARÃES, J. R. D.; ROULET, M.; LUCOTTE, M.; MERGLER, D. Hg methylation along a lake-forest transect in the Tapajos river floodplain, Brazilian Amazon: seasonal and vertical variations. Sci. Total Environ., v. 261, p. 91-98, 2000b.

HESS, L. L.; MELACK J. M.; NOVO, E. M. L. M.; BARBOSA, C. C. F.; GASTIL, M. Dual-season mapping of wetland inundation and vegetation for the central Amazon basin. Remote Sensing of Environment, v. 87, p. 404-428, 2003.

HESS, L. L.; NOVO, E. M, L. M.; SLAYMAKER, D. M.; HOLT, J.; STEFFEN, C.; VALERIANO, D. M.; MERTES, L. A. K.; KRUG, T.; MELACK, J. M.; GASTIL, M.; HOLMES, C.; HAYWARD, C. Geocoded digital videography for validation of land cover mapping in the Amazon basin. Int. J. Remote Sensing, v. 23 , n. 7, p. $1527-1556,2002$.

IBGE. Dados do município de Santarém/PA. 2010. Disponível em: < http:/ / www.ibge.gov.br/cidadesat>. Acesso em: 21 out. 2011.

LECHLER, P. J.; MILLER, J. R.; LACERDA, L. D.; VINSON, D.; BONZONGO, J. C.; LYONS, W. B. ; WARWICK, J. J. Elevated mercury concentrations in soils, sediments, water, and fish of the Madeira River Basin, Brazilian Amazon: a function of natural enrichment? Sci. Total Environ., v. 26, p. 87-96, 2000.

LUCAS, Y.; BOULET, R. ; CHAUVEL, A. ; VEILLON, L. Systèmes Sols Ferralitiques-Podzols en Region Amazonienne. In: RIGHI, D.; CHAUVEL, A. (Eds.). Podzol et Podzolisation. Poitiers : AFES/INRA, 1986. p. 53-65.

MASCARENHAS, A. F. S. et al. Avaliação da concentração de mercúrio em sedimentos e material particulado no Rio Acre, estado do Acre, Brasil. Acta Amazonica, Manaus, v. 34, n. 1, p. 61-68, 2004. 
MASON, R.P.; FITZGERALD, W.F.; MOREL, F.M.M. The biogeochemical cycling of elemental mercury: Anthropogenic influences. Geochim. Cosmochim. Acta, v. 58, p. 3191-3198, 1994.

NRIAGU, J. O. Mercury pollution from the past mining of gold and silver in the Americas. Sci Total Environ., v. 149, p.167-181, 1994.

PADOVANI, C. R.; FORSBERG, B. R.; PIMENTEL, T. P. Contaminação em peixes do rio Madeira: Resultados e recomendações para consumo humano. Acta Amazônica, v. 25, n. 1/2, p.127-136, 1994.

PARÁ. Governo do Estado. Estatítica Municipal. Jacareacanga: Secretaria de Estado de Planejamento, Orçamento e Finanças; Instituto de Desenvolvimento Econômico, Social e Ambiental do Pará, 2011.

PELEJA, J. R. P. Balanço de massas de mercúrio (Hg) total em duas microbacias da Amazônia Central. 2007. 123 f. Tese (Doutorado em Biologia de Água Doce e Pesca Interior) - Instituto Nacional de Pesquisas da Amazônia, 2007.

PELEJA, J. R. P. Os fatores que influem nos nível de mercúrio (Hg) na água e plankton de lagos associados aos rios Tapajós e Negro. 2002. 73f. Dissertação (Mestrado) - Instituto Nacional de Pesquisas da Amazônia; Universidade Federal do Amazonas, Manaus, 2002.

RESENDE, M; CURI, N.; REZENDE, S. B.; CORRÊA, G. F. Pedologia: base para distinção de ambientes. 5. ed. rev. Lavras: Ed. UFLA, 2007.

ROSENQVIST, A.; FORSBERG, B. R.; PIMENTEL, T. P.; RAUSCH, Y. A.; RICHEY, J. E. The use of spaceborne radar data to model inundation patterns and trace gas emissions in the Central Amazon floodplain. International Journal of Remote Sensing, v. 23, p.1303-1328, 2002.

ROULET, M.; GUIMARÃES, R. R. D.; LUCOTTE, M. MethylHg production and accumulation in sediments and soils of an Amazonian floodplain - effect of seasonal inundation. Water Air Soil Pollut., v, 8, p. 41-60, 2001 a.

ROULET, M.; LUCOTTE, M.; CANUEL, R.; RHEAULT, I.; TRAN, S.; GOGH, Y. G. F.; FARELLA, N.; VALLE, R. S.; PASSOS, C. J. S.; SILVA, J. E.; MERGLER, D.; AMORIM, M. Distribution and partition of total mercury in waters of the Tapajós river basin, Brazilian Amazon. Sci. Total Environ., v. 213, p. 203-211, 1998 b. 
ROULET, M.; LUCOTTTE, M.; GUIMARÃES, J. R. D.; RHEAL, I. MethylHg in water, seston, and epiphyton of Amazonian river and its floodplain, Tapajós River, Brazil. Sci. Total Environ., v. 261, p. 43-59, 2000 b.

ROULET, M.; LUCOTTE, M.; SAINT-AUBIN, A.; TRAN, S. ; RHEAULT, I. ; FARELLA, N. et al. The geochemistry of $\mathrm{Hg}$ in Central Amazonian soil developed on the Alter do Chão formation of the lower Tapajós River Valley, Pará state, Brazil. Sci. Total Environ., v. 223, p.1-24, 1998a.

ROULET, M; LUCOTTE, M. Geochemistry of mercury in pristine and flooded ferralitic soils of a tropical rain forest in French Guiana, South America. Water Air Soil Pollut., v. 80, p.1079-1088, 1995.

SILVA-FORSBERG, M. C.; FORSBERG, B. R.; ZEIDEMAN, V. K. Mercury contamination in humans linked to river chemistry in the Amazon basin. Royal Swedish Academy of Sciences, v. 28, p. 519-521, 1999.

SOUSA, E. S. Uso integrado de dados de sensoriamento remoto para o estudo da geologia e geomorfologia da área da foz do rio Tapajós, Santarém-PA. 2009. Dissertação (Mestrado em Geociências) - Universidade Federal do Amazonas, Manaus, 2009.

SOUZA, T. M. C. Manual de análises de mercúrio. Tradução de Terezinha M. Cid de Souza. Brasília, DF: Ministério do Meio Ambiente - MMA, Japão, 2004.

TIBIRIÇA, L. G. Caracterização geoquímico-ambiental do garimpo do Tucano, Monte Alegre de Goiás-GO. 2006. Dissertação (Mestrado em Geografia) - IESA/Universidade federal de Goiás. Goiânia, 2006.

WASSERMAN, J. C.; HACON, S. S.; WASSERMAN, M. A. O ciclo do mercúrio no ambiente amazônico. Mundo \& Vida, v. 2, n. 1/2, 2001

ZEIDEMANN, V. K. A geoquímica de mercúrio em solos da bacia do rio Negro e sua influência no ciclo regional do mercúrio. 1999. Dissertação (Mestrado em Ecologia) - Instituto Nacional de Pesquisas da Amazônia; Universidade do Amazonas, Manaus, 1999.

ZONEAMENTO Ecológico-Econômico da BR-163 - ZEE BR-163. Disponível em: <http://zeebr163.cpatu.embrapa.br/index.php>. Acesso em: 20 set. 2008. 


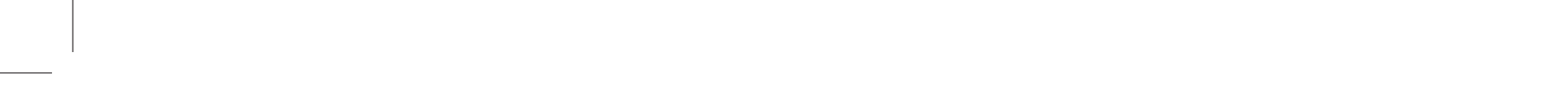

